\title{
Endogenous timing of moves in an asymmetric price-setting duopoly
}

\author{
Attila Tasnádi* \\ Department of Economics, University of Bonn, D-53113 Bonn, \\ Adenauerallee 24-42, Germany ${ }^{\dagger}$ \\ Department of Mathematics, Budapest University of Economic Sciences \\ and Public Administration, H-1093 Budapest, Fővám tér 8, Hungary
}

February 13, 2003.

Appeared in the Portuguese Economic Journal 2(2003) p. 23-35, (C) Springer-Verlag.

\begin{abstract}
This paper adds to the growing literature on endogenous timing of decisions in duopolies. We show for a price-setting duopoly game with sufficiently asymmetric and strictly convex cost functions that the less efficient firm moves first while the more efficient moves second with a higher price than the less efficient firm.

Keywords: Price-setting games; Price leadership; Dominant firm.

JEL classification: D43; L13.
\end{abstract}

\section{Introduction}

There is a growing literature on endogenous timing of decisions in oligopolies, which mainly focuses on duopolies. ${ }^{1}$ Gal-Or (1985), Dowrick (1986) and Boyer and Moreaux (1987) compared the outcomes of exogenous timing duopoly games in order to find out whether the leader or the follower has a more advantageous position. They also identified conditions under which

\footnotetext{
${ }^{*}$ I am grateful to Dan Kovenock and the anonymous referees for many comments and suggestions on an earlier version of this paper. Parts of this research were done during the author's Bolyai János Research Fellowship provided by the Hungarian Academy of Sciences (MTA)

${ }^{\dagger}$ Telephone: (+49 228) 739490, E-mail: attila.tasnadi@wiwi.uni-bonn.de

${ }^{\ddagger}$ Telephone: (+36 1) 4566782, E-mail: attila.tasnadi@math.bke.hu

${ }^{1}$ Oligopolies have been investigated for example by Gangopadhyay (1993) and Matsumura (1999).
} 
conflict emerges between the two firms to obtain the leader or follower position. The more recent literature aims to solve the conflict concerning roles, and determines an endogenous order of moves under certain circumstances. Papers addressing this issue include Hamilton and Slutsky (1990), Deneckere and Kovenock (1992), Furth and Kovenock (1993), van Damme and Hurkens (1998, 1999) and Matsumura (1999, 2002), among others.

For price-setting duopoly games we determine the endogenous order of moves in the framework of a Bertrand-Edgeworth game with strictly convex and sufficiently asymmetric cost functions. We obtain the following interesting result: The more efficient firm chooses the follower's position, while the less efficient firm selects the leader's position (Theorem 3). This result can be interpreted in the following way: The more efficient firm is exerting power from the follower's position by forcing the less efficient firm, which has to avoid the possibility of being undercut by the more efficient firm, to set a sufficiently low price. This result has been obtained in the Bertrand-Edgeworth framework by Boyer and Moreaux (1987), Deneckere and Kovenock (1992) as well as Canoy (1996) in different settings.

Boyer and Moreaux (1987) considered a homogeneous good price-setting duopoly game in which the firms simultaneously choose their prices and quantities. They found that for small cost differentials both firms prefer the follower's position, while for large cost differentials there is no conflict concerning the order of moves since the less efficient firm chooses the role of the leader and the more efficient firm chooses the role of the follower. However, they did not deal with the possibility of simultaneous moves and compared only the outcome of two sequential-move games in determining the order of moves. In this respect our main result is that the possibility of simultaneous moves does not alter their finding concerning the endogenous order of moves in the Bertrand-Edgeworth framework if the two firms have sufficiently asymmetric cost functions. We have to mention that our assumptions differ in three main points from theirs. First, they considered only linear demand and cost functions. Second, they employed the proportional rationing rule while we use the efficient rationing rule. ${ }^{2}$ Third, we consider the productionto-order version of the Bertrand-Edgeworth game in which production takes place after the firms have already fixed their prices.

Deneckere and Kovenock (1992) determined the endogenous order of decisions in a homogeneous good Bertrand-Edgeworth duopoly game with capacity constraints in which they also allowed for the possibility of simultaneous moves. They investigated the case of constant unit costs up to the firms' ca-

\footnotetext{
${ }^{2}$ For the definitions of these two rationing rules we refer to Tirole (1988) and Vives (1999).
} 
pacity constraints. As a function of the unit costs and the capacity constraints they derived the endogenous order of moves. In this respect we consider a setting which is more difficult to analyze, since for the simultaneous-move game there is not much known beyond the existence of a mixed-strategy equilibrium in case of convex cost functions.

Finally, Canoy (1996) considered a heterogeneous goods Bertrand-Edgeworth duopoly game for which he also showed that the less efficient firm moves first. However, as in Boyer and Moreaux (1987) he did not allow the firms to move simultaneously.

The remainder of this paper is organized as follows. In Section 2 we describe the framework of our analysis. In Section 3 we investigate a simple two-period timing game, while a multi-period timing game is considered in Section 4. We conclude our paper in Section 5.

\section{The framework}

The demand is given by the function $D: \mathbb{R}_{+} \rightarrow \mathbb{R}_{+}$on which we impose the following assumptions in order to ensure the existence of equilibrium:

Assumption 1. There exists a positive price $b$ such that $D(p)>0$ if $p<b$, and $D(p)=0$ if $p \geq b$. The demand function $D$ is continuous, strictly decreasing on $[0, b]$, and continuously differentiable on $(0, b)$.

Let $a$ be the horizontal intercept of the demand function, i.e., $D(0)=a$. Clearly, any firm will not set its price above $b$ in the price-setting game.

We denote the firms' cost functions by $c_{i}:[0, a] \rightarrow \mathbb{R}_{+}(i \in\{1,2\})$. In order to ensure the existence and at some points also the uniqueness of the equilibrium through our analysis we impose on the firms' cost functions the following assumptions:

Assumption 2. The cost functions $c_{i}$ are twice continuously differentiable, there are no fixed costs and the cost functions are strictly increasing and strictly convex. Furthermore, $c_{i}^{\prime}(0)=\lim _{q \rightarrow 0^{+}} c_{i}^{\prime}(q)=m c_{i}(0)<b$ for all $i \in\{1,2\}$.

Assumption 2 also implies that the competitive supply, henceforth briefly supply, at price level $p \in[0, b]$ of firm $i$ can be given by

$$
s_{i}(p):= \begin{cases}a, & \text { if } p \in\left(m c_{i}(a), b\right] \\ \left(m c_{i}\right)^{-1}(p), & \text { if } p \in\left[m c_{i}(0), m c_{i}(a)\right] \cap[0, b], \\ 0, & \text { if } p \in\left[0, m c_{i}(0)\right)\end{cases}
$$


because the supply of firm $i$ at price level $p$ is a solution of the problem $s_{i}(p)=\arg \max _{q \in[0, a]} p q-c_{i}(q)$, which has a unique solution for all $p \geq 0$ because of Assumption 2. In addition, there exists an interval of prices such that $s_{i}(p)=\left(m c_{i}\right)^{-1}(p)$. We shall denote by $p^{c}$ the price at which demand equals supply, i.e., $D\left(p^{c}\right)=s_{1}\left(p^{c}\right)+s_{2}\left(p^{c}\right)$.

The following technical assumption ensures that both firms will be active in the market:

Assumption 3. $s_{1}\left(p^{c}\right)>0$ and $s_{2}\left(p^{c}\right)>0$.

Since we do not want to assume that the firms are not producing beyond their competitive supplies, we start with defining a price-quantity game. The price and quantity decisions of firm $i \in\{1,2\}$ are given by $\left(p_{i}, q_{i}\right) \in[0, b] \times[0, a]$. The quantity decisions $q_{1}$ and $q_{2}$ mean here the amounts actually produced by the firms. We assume that the price decisions precede the quantity decisions, that is, we consider a production-to-order type market environment. In addition, we suppose that the firms make their quantity decisions simultaneously after they have already announced their prices in a certain order. Concerning the order of price decisions we will analyze two sequential-move games (differing in the order of moves) and the simultaneousmove game. In particular, in the games with sequential price moves we have either firm 1 or firm 2 announcing its price in stage one, the other firm announcing its price in stage two and both firms making production decisions simultaneously in stage three; while in the game with simultaneous price moves we have firms 1 and 2 setting their prices simultaneously in stage one and firms 1 and 2 making their production decisions simultaneously in stage two.

In specifying the firms' demands we assume efficient rationing ${ }^{3}$ of consumers, which occurs in a market if the consumers are able to costlessly resell the good to each other, or if the consumers have heterogeneous unit demands and the consumers having higher reservation prices are served first (for more details we refer to Tirole, 1988; and Vives, 1999). For price ties we define the demands differently for the games with sequential price moves and the game with simultaneous price moves: Let $T_{1}\left(p, q_{2}\right):=\left(D(p)-q_{2}\right)^{+}$and $T_{2}\left(p, q_{1}\right):=D(p)$ in the two games with sequential price moves, and

$$
T_{i}\left(p, q_{j}\right):=\max \left\{\frac{s_{i}(p)}{s_{i}(p)+s_{j}(p)} D(p), D(p)-q_{j}\right\}
$$

in the game with simultaneous price moves, where, like throughout the paper, $i, j \in\{1,2\}$ and $i \neq j$. This distinction ensures that the two games with

\footnotetext{
${ }^{3}$ Efficient rationing is also called parallel rationing (see for instance Tirole, 1988) and surplus-maximizing rationing (see for example Vives, 1999).
} 
sequential price moves have a unique equilibrium and we do not have to consider $\varepsilon$-equilibrium solutions. We define the demand faced by the firms in the following manner:

$$
\Delta_{i}\left(p_{i}, q_{i}, p_{j}, q_{j}\right):=\left\{\begin{array}{lll}
D\left(p_{i}\right), & \text { if } p_{i}<p_{j} \\
T_{i}\left(p_{i}, q_{j}\right), & \text { if } p_{i}=p_{j} \\
\left(D\left(p_{i}\right)-q_{j}\right)^{+}, & \text {if } p_{i}>p_{j} .
\end{array}\right.
$$

Since the firms' sales are either demand constrained or production constrained, their sales equal $\min \left\{\Delta_{i}\left(p_{i}, q_{i}, p_{j}, q_{j}\right), q_{i}\right\}$. Now we are ready to define the profit functions of the price-quantity game as

$$
\tilde{\pi}_{i}\left(p_{i}, q_{i}, p_{j}, q_{j}\right):=p_{i} \min \left\{\Delta_{i}\left(p_{i}, q_{i}, p_{j}, q_{j}\right), q_{i}\right\}-c_{i}\left(q_{i}\right) .
$$

By solving the quantity-setting stage of the price-quantity game we obtain the price-setting game, which we will analyze in Sections 3 and 4 . If firm $i$ is the low-price firm, then

$$
\tilde{\pi}_{i}\left(p_{i}, q_{i}, p_{j}, q_{j}\right)=p_{i} \min \left\{D\left(p_{i}\right), q_{i}\right\}-c_{i}\left(q_{i}\right)
$$

and firm $i$ 's optimal production will be

$$
q_{i}=\min \left\{D\left(p_{i}\right), s_{i}\left(p_{i}\right)\right\} .
$$

Hence, the high-price firm $j$ maximizes $\tilde{\pi}_{j}\left(p_{j}, q_{j}, p_{i}, \min \left\{D\left(p_{i}\right), s_{i}\left(p_{i}\right)\right\}\right)=$

$$
p_{j} \min \left\{\left(D\left(p_{j}\right)-\min \left\{D\left(p_{i}\right), s_{i}\left(p_{i}\right)\right\}\right)^{+}, q_{j}\right\}-c_{j}\left(q_{j}\right)
$$

in $q_{j}$ and we obtain as the solution of this problem that firm $j$ produces

$$
q_{j}=\min \left\{\left(D\left(p_{j}\right)-s_{i}\left(p_{i}\right)\right)^{+}, s_{j}\left(q_{j}\right)\right\} .
$$

Now we turn to the case of equal prices. For the two games with sequential moves we can derive in case of price ties $\left(p=p_{1}=p_{2}\right)$ that

$$
q_{1}=\min \left\{\left(D(p)-s_{2}(p)\right)^{+}, s_{1}(p)\right\}, q_{2}=\min \left\{D(p), s_{2}(p)\right\} .
$$

In the game with simultaneous price moves firm $i$ can sell $\frac{s_{i}(p)}{s_{i}(p)+s_{j}(p)} D(p)$ independently of the other firm's action because of our tie-breaking rule. The same holds true for firm $j$. Hence, at price $p=p_{1}=p_{2}$ firm $i$ will produce

$$
q_{i}=\min \left\{\frac{s_{i}(p)}{s_{i}(p)+s_{j}(p)} D(p), s_{i}(p)\right\} .
$$


Taking the solutions of the quantity-setting subgames (1), (2), (3) and (4) into consideration we can restrict ourselves from now on to the analysis of the price-setting game $O_{p}:=\left\langle\{1,2\},[0, b]^{2},\left(\pi_{1}, \pi_{2}\right)\right\rangle$, where

$$
\pi_{i}\left(p_{i}, p_{j}\right)=p_{i} \min \left\{D\left(p_{i}\right), s_{i}\left(p_{i}\right)\right\}-c_{i}\left(\min \left\{D\left(p_{i}\right), s_{i}\left(p_{i}\right)\right\}\right)
$$

if firm $i$ is the low-price firm,

$$
\pi_{i}(p, p)=p \min \left\{T_{i}\left(p, s_{j}(p)\right), s_{i}(p)\right\}-c_{i}\left(\min \left\{T_{i}\left(p, s_{j}(p)\right), s_{i}(p)\right\}\right)
$$

if there is a price tie and $\pi_{i}\left(p_{i}, p_{j}\right)=$

$$
p_{i} \min \left\{\left(D\left(p_{i}\right)-s_{j}\left(p_{j}\right)\right)^{+}, s_{i}\left(p_{i}\right)\right\}-c_{i}\left(\min \left\{\left(D\left(p_{i}\right)-s_{j}\left(p_{j}\right)\right)^{+}, s_{i}\left(p_{i}\right)\right\}\right)
$$

if firm $i$ is the high-price firm.

We shall denote by $D_{i}^{r}(p):=\left(D(p)-s_{j}(p)\right)^{+}$the residual demand of firm $i$ in all three games ${ }^{4}$, which 'almost' equals the demand of firm $i$ if it is 'just' undercut by its opponent $j$. In particular, in the sequential games $D_{1}^{r}(p)$ simply equals the demand firm 1 faces if firm 2 matches firm 1's price, whereas in any other case we have

$$
D_{i}^{r}(p)=\lim _{p_{j} \rightarrow p^{-}} \Delta_{i}\left(p, s_{i}(p), p_{j}, s_{j}\left(p_{j}\right)\right)<\Delta_{i}\left(p, s_{i}(p), p, s_{j}(p)\right)
$$

for any $p>p^{c}$. Let

$$
\begin{aligned}
\pi_{i}^{*} & :=\max _{p \in[0, b]} \tilde{\pi}_{i}\left(p, D_{i}^{r}(p), p, s_{j}(p)\right), \\
P_{i}^{*} & :=\arg \max _{p \in[0, b]} \widetilde{\pi}_{i}\left(p, D_{i}^{r}(p), p, s_{j}(p)\right) .
\end{aligned}
$$

Clearly, firm $i$ can secure at least $\pi_{i}^{*}$ profits. Define the set

$$
\left.L_{i}:=\left\{p \in[0, b] \mid p \min \left\{D(p), s_{i}(p)\right\}-c_{i}\left(\min \left\{D(p), s_{i}(p)\right\}\right)=\pi_{i}^{*}\right)\right\}
$$

consisting of those prices for which firm $i$ is indifferent between serving the entire market or maximizing its profit with respect to its residual demand curve. Note that $L_{i}$ is non-empty because of Assumptions 1 and 2, but may contain more than one element although in many cases $L_{i}$ contains only one element. Let $p_{i}^{L}:=\min L_{i}$. Firm $i$ will never set its price below $p_{i}^{L}$ because any price $p<p_{i}^{L}$ is dominated by any price $p^{*} \in P_{i}^{*}$. It can be easily checked that by Assumptions 1, 2 and 3 we have $p^{*}>p_{i}^{L}>p^{c}$ for any price $p^{*} \in P_{i}^{*}$.

The following assumption implies that the two firms are asymmetric:

\footnotetext{
${ }^{4}$ This is the worst that could happen to firm $i$ if it sets price $p$.
} 
Assumption 4. For all $p \geq p_{1}^{L}$ we have $D(p)<s_{1}(p)$.

Assumption 4 means that firm 1 is willing to serve the entire demand for all its undominated prices. Therefore, we call firm 1 the more efficient firm and its opponent, firm 2, the less efficient firm. It can be verified that, for example, the duopoly market with demand curve $D(p)=1-p$ and cost functions $c_{1}(q)=\alpha q^{2}, c_{2}(q)=q^{2}$ satisfies Assumption 4 whenever $0<\alpha \leq$ $(-1+\sqrt{6}) / 5 \approx 0.2899$. However, Assumption 4 excludes cases in which the two firms do not have sufficiently asymmetric cost functions, for instance, if $D(p)=1-p, c_{1}(q)=\alpha q^{2}$ and $c_{2}(q)=q^{2}$, then Assumption 4 is violated for any $\alpha>(-1+\sqrt{6}) / 5$. Therefore, we have to explain why we need Assumption 4 throughout our analysis: The main problem is that there is not much known beyond the existence ${ }^{5}$ of a mixed-strategy equilibrium in homogeneous good Bertrand-Edgeworth games with convex cost functions. Hence, Assumption 4 makes the comparison of the equilibrium profits of the simultaneous-move game and the two sequential-move games possible.

After all, we define $\widetilde{p}$ to be the price at which the less efficient firm could satisfy the entire demand; that is, $s_{2}(\widetilde{p})=D(\widetilde{p})$. It can be checked that $\widetilde{p}>p_{1}^{L}$.

\section{A two-period timing game}

In this section we investigate a two-period timing game in which the firms themselves can choose between two periods to make their price announcements. After the firms have made their timing decisions, which they all observe, they will play the corresponding price-setting game introduced in Section 2. This two-period timing game appeared in Deneckere and Kovenock (1988) applied to Bertrand-Edgeworth duopoly games with capacity constraints. A similar timing game appeared also in Hamilton and Slutsky (1990) for games possessing pure-strategy equilibria. They called such kind of timing games 'games with observable delay'. To determine the endogenous order of moves we have to compare the equilibrium profits of the three price-setting games defined in Section 2.

We start with the sequential-move game in which firm 1 is the exogenously given first mover.

Proposition 1. Consider a duopoly market satisfying Assumptions 1-4. If the more efficient firm is the exogenously given first mover, then in any subgame-perfect Nash equilibrium the more efficient firm selects a price $p^{*}$ from set $P_{1}^{*}$ and the less efficient firm follows with the same price.

\footnotetext{
${ }^{5}$ The existence of a mixed-strategy equilibrium was established by Maskin (1986).
} 
Proof. We already noted that the more efficient firm will not set its price below $p_{1}^{L}$. Hence, let the more efficient firm's action be any price $p \in\left[p_{1}^{L}, b\right]$. Then $s_{1}(p)+s_{2}(p)>D(p)$ holds true. We have to consider two different cases: (i) $s_{2}(p)<D(p)$, i.e, $p<\widetilde{p}$ and (ii) $s_{2}(p) \geq D(p)$, i.e, $p \geq \widetilde{p}$.

In case (i) firm 2 will not set its price below $p$ because at price $p$ firm 2 can sell its entire supply. By setting a price $p_{2}>p$ firm 2 cannot sell anything at all, since by Assumption 4 we have $D\left(p_{2}\right)-s_{1}\left(p_{2}\right) \leq 0$ for all $p_{2}>p$. Therefore, $p_{2}=p$ is a Nash equilibrium of the subgame. We conclude that at price $p$ the more efficient firm will sell $\min \left\{D(p)-s_{2}(p), s_{1}(p)\right\}=$ $D(p)-s_{2}(p)$ amount of product.

In case (ii) firm 2 will not set its price below $\widetilde{p}$ because price $\widetilde{p}$ dominates any lower price, since at price $\widetilde{p}$ firm 2 can sell its entire supply. Clearly, the less efficient firm will not set a price higher than $p$ because of Assumption 4 . Hence, Assumption 2 implies that firm 2 will serve the entire demand, which means that firm 1 will not set a price above $\widetilde{p}$.

Finally, we conclude that the more efficient firm will set its price by maximizing its profit with respect to its residual demand curve because we have established that the more efficient firm chooses its price from the interval $\left[p_{1}^{L}, \widetilde{p}\right]$ and that for such prices the less efficient firm behaves as a price taker.

We have to mention that if we specify a different tie-breaking rule for the case of equal prices, then the solution in Proposition 1 can only be an $\varepsilon$ equilibrium. To see this we have to observe that if the less efficient firm faces less demand than $s_{2}\left(p_{1}\right)$, then it will undercut price $p_{1}$ for all $p_{1} \in\left[p_{1}^{L}, \widetilde{p}\right]$.

Now we compare the sequential-move game in which the more efficient firm moves first with the simultaneous-move game. Specifically, we demonstrate that firm 1 announcing its price in the first time period and firm 2 announcing its price in the second time period is not a subgame-perfect Nash equilibrium of the timing game, which is surprising since the more efficient firm will not become a price leader.

From Maskin (1986) it follows that under our Assumptions 1 and 2 the simultaneous-move price-setting game has an equilibrium in mixed strategies. Let us denote by $\pi_{i}\left(\varphi_{1}, \varphi_{2}\right)$ the expected profit obtained by firm $i$ in case of the mixed-strategy profile $\left(\varphi_{1}, \varphi_{2}\right)$. The next proposition establishes that firm 1 will not accept the role of the leader.

Proposition 2. Suppose that the duopoly market satisfies Assumptions 1-4. If $\left(\varphi_{1}^{*}, \varphi_{2}^{*}\right)$ is a mixed-strategy equilibrium of the simultaneous-move pricesetting game, then

$$
\pi_{1}\left(\varphi_{1}^{*}, \varphi_{2}^{*}\right) \geq \pi_{1}\left(p_{1}^{*}, \varphi_{2}^{*}\right)>\pi_{1}^{*}
$$


for any $p_{1}^{*} \in P_{1}^{*}$; that is, the more efficient firm prefers playing the simultaneous-move price-setting game to accepting the role of the price leader.

Proof. Clearly, each firm $i \in\{1,2\}$ setting its price with probability one to $p_{1}^{*} \in P_{1}^{*}$ cannot be a Nash equilibrium profile of the simultaneous-move game because then firm 1 will slightly undercut price $p_{1}^{*}$ by Assumption 3 . Hence, in any mixed-strategy Nash equilibrium firm 2 sets prices differently from $p_{1}^{*}$ with positive probability. Clearly, if firm 2 sets a higher price than $p_{1}^{*}$, then firm 1 faces the entire demand at price $p_{1}^{*}$ and can sell more than $D_{1}^{r}\left(p_{1}^{*}\right)$. Now if firm 2 sets price $p_{2}$ below $p_{1}^{*}$, it supplies only $s_{2}\left(p_{2}\right)$ which is less than $s_{2}\left(p_{1}^{*}\right)$ because of Assumption 2 and it follows that firm 1 can sell at price $p_{1}^{*}$ more than $D_{1}^{r}\left(p_{1}^{*}\right)$. Hence, firm 1 can sell at price $p_{1}^{*}$ more than $D_{1}^{r}\left(p_{1}^{*}\right)$ amount of product with positive probability. Thus, $\pi_{1}\left(p_{1}^{*}, \varphi_{2}^{*}\right)>\pi_{1}^{*}$. Obviously $\pi_{1}\left(\varphi_{1}^{*}, \varphi_{2}^{*}\right) \geq \pi_{1}\left(p_{1}^{*}, \varphi_{2}^{*}\right)$ must hold.

The reason why the more efficient firm prefers moving simultaneously to moving first is that at any leader price $p_{1}^{*} \in P_{1}^{*}$ it sells with positive probability more than its residual demand $D_{1}^{r}\left(p_{1}^{*}\right)$ because its opponent is playing a nondegenerated mixed-strategy in the simultaneous-move pricesetting game.

We have to determine the outcome of the game in which the less efficient firm is the first mover. As we already noted in Section 2 the more efficient firm will never set its price below $p_{1}^{L}$. Thus, the less efficient firm can sell its entire supply if it sets a price less than or equal to $p_{1}^{L}$, which implies (regarding Assumptions 1 and 2) that the less efficient firm too will not set its price below $p_{1}^{L}$. Moreover, the less efficient firm has to set its price so that the more efficient firm will not undercut the less efficient firm, because otherwise the more efficient firm would capture the entire market because of Assumption 4 and thus, the less efficient firm will not sell anything at all. The more efficient firm's sales equal $D(p)$ for all $p \geq p_{1}^{L}$ if it undercuts the less efficient firm. Let $h\left(p_{1}, p_{2}\right):=\min \left\{s_{1}\left(p_{1}\right),\left(D\left(p_{1}\right)-s_{2}\left(p_{2}\right)\right)^{+}\right\}\left(p_{1} \geq p_{2} \geq p_{1}^{L}\right)$ stand for the amount sold by the more efficient firm if it sets the higher or the same price. Furthermore, we shall denote by $G(p):=p D(p)-c_{1}(D(p))$ and $H\left(p_{1}, p_{2}\right):=p_{1} h\left(p_{1}, p_{2}\right)-c_{1}\left(h\left(p_{1}, p_{2}\right)\right)$ the profit levels corresponding to the two previously mentioned cases. The function $\pi^{h}\left(p_{2}\right):=\max _{p_{1} \in\left[p_{2}, b\right]} H\left(p_{1}, p_{2}\right)$ gives the maximum profit if the more efficient firm does not undercut the less efficient firm's price $p_{2} .{ }^{6}$ Observe that if $p_{1}^{L} \leq p_{2}<p_{2}^{\prime} \leq \widetilde{p}$, then for any $p_{1} \in$ $\left[p_{2}^{\prime}, \widehat{p}\right)$, where $\widehat{p}$ is determined by $D(\widehat{p})=s_{2}\left(p_{2}\right)$, we have $H\left(p_{1}, p_{2}\right)>H\left(p_{1}, p_{2}^{\prime}\right)$ because of Assumption 2 and therefore, it follows that $\pi^{h}\left(p_{2}\right)>\pi^{h}\left(p_{2}^{\prime}\right)$.

\footnotetext{
${ }^{6}$ Deneckere and Kovenock (1992) introduced similar functions in analyzing the pricesetting game with capacity constraints.
} 
Moreover, $\pi^{h}$ is a continuous function following from the Theorem of the Maximum. Thus, the less efficient firm's price $p_{2}^{l}$ is determined by the smallest price satisfying equation $G\left(p_{2}\right)=\pi^{h}\left(p_{2}\right)$, which has a solution in $\left[p_{1}^{L}, \widetilde{p}\right]$, since $G\left(p_{1}^{L}\right)=\pi_{1}^{*}<\pi^{h}\left(p_{1}^{L}\right)$ and $G(\widetilde{p})>\pi^{h}(\widetilde{p})=0$. In particular, the less efficient firm has to pick the smallest price satisfying equation $G\left(p_{2}\right)=\pi^{h}\left(p_{2}\right)$ because $\pi^{h}$ is strictly decreasing on $\left[p_{1}^{L}, \widetilde{p}\right]$. In a subgame-perfect Nash equilibrium firm 1 sets its price $p_{1}^{h}$ by maximizing function $H\left(\cdot, p_{2}^{l}\right)$. Note that under Assumptions 1-4 there may be multiple prices $p_{1}^{h}$ maximizing $H\left(\cdot, p_{2}^{l}\right)$.

Based on the results obtained so far we can formulate and prove the following theorem.

Theorem 3. Suppose that the duopoly game satisfies Assumptions 1-4. Then the less efficient firm moves first and the more efficient firm moves second. Furthermore, the less efficient firm sets price $p_{2}^{l}$ and the more efficient firm sets a price $p_{1}^{h}$, which maximizes function $H\left(\cdot, p_{2}^{l}\right)$ and is higher than $p_{2}^{l}$.

Proof. We know by Proposition 2 that the more efficient firm will not be the price leader. Therefore, it remains to show that both firms prefer the game having the less efficient firm as the first mover to the simultaneousmove price-setting game. Let $\left(\varphi_{1}, \varphi_{2}\right)$ be a mixed-strategy equilibrium of the simultaneous-move game. We write $p_{i}:=\min \operatorname{supp} \varphi_{i}$ for the smallest price in the support of $\varphi_{i}$ and $\bar{p}_{i}:=\max \operatorname{supp} \varphi_{i}$ for the largest price in the support of $\varphi_{i}(i \in\{1,2\})$. Obviously, $\underline{p}_{1} \geq p_{1}^{L}$. Clearly $\underline{p}_{2}<\widetilde{p}$ because otherwise $\pi_{2}\left(\varphi_{1}, \varphi_{2}\right)=0$ if $\bar{p}_{1}<\bar{p}_{2}, \pi_{1}\left(\varphi_{1}, \varphi_{2}\right)=0$ if $\bar{p}_{1}>\bar{p}_{2}, \pi_{i}\left(\varphi_{1}, \varphi_{2}\right)=0$ if $\bar{p}_{1}=\bar{p}_{2}$ and $\varphi_{j}\left(\left\{\bar{p}_{j}\right\}\right)=0$, and each firm can increase its profit by undercutting its opponent price with probability $\varphi_{i}\left(\left\{\bar{p}_{i}\right\}\right)$ if both firms have an atom at price $\bar{p}_{1}=\bar{p}_{2}$.

We will need the following four auxiliary statements: (i) $\underline{p}_{1} \leq \underline{p}_{2}$, (ii) $\bar{p}_{1} \geq \bar{p}_{2}$, (iii) $\varphi_{2}\left(\left\{\underline{p}_{2}\right\}\right)=0$ and (iv) $\varphi_{2}\left(\left\{\bar{p}_{1}\right\}\right)=0$. The first one $\underline{p}_{1} \leq \underline{p}_{2}$ must hold true since otherwise a profile with $\underline{p}_{2}<\underline{p}_{1}$ could not be an equilibrium profile because firm 2 would sell its entire supply by setting a price in interval $\left[\underline{p}_{2}, \min \left\{\underline{p}_{1}, \widetilde{p}\right\}\right)$ and thus its profits would increase on $\left[\underline{p}_{2}, \min \left\{\underline{p}_{1}, \widetilde{p}\right\}\right)$. For the second one observe that if firm 2 sets a higher price than $\bar{p}_{1}$, then it will not sell anything at all regarding Assumption 4. In order to verify the third one suppose that $\varphi_{2}$ has an atom at $\underline{p}_{2}$, i.e., $\alpha:=\varphi_{2}\left(\left\{\underline{p}_{2}\right\}\right)>0$. We have to distinguish between two cases. If there exists a positive value $\varepsilon$ such that $\varphi_{1}\left(\left[\underline{p}_{2}, \underline{p}_{2}+\varepsilon\right)\right)=0$ holds true, then firm 2 could benefit from increasing the probability of setting a price in interval $\left(\underline{p}_{2}, \underline{p}_{2}+\varepsilon\right)$ with the additional probability of $\alpha$ and never setting price $\underline{p}_{2}$. If we have $\varphi_{1}\left(\left[\underline{p}_{2}, \underline{p}_{2}+\varepsilon\right)\right)>0$ for all positive values $\varepsilon$, then we can select a sufficiently small positive value $\varepsilon^{\prime}$ such that firm 1 could gain from undercutting price $\underline{p}_{2}$ with probability of $\beta:=\varphi_{1}\left(\left[\underline{p}_{2}, \underline{p}_{2}+\varepsilon^{\prime}\right)\right)$ and never setting prices in interval $\left[\underline{p}_{2}, \underline{p}_{2}+\varepsilon^{\prime}\right)$. Now we 
turn to statement (iv). Suppose that this is not the case, i.e., $\varphi_{2}\left(\left\{\bar{p}_{1}\right\}\right)>0$. Then by (ii) we must have $\bar{p}_{1}=\bar{p}_{2}$. If $\varphi_{1}\left(\left\{\bar{p}_{1}\right\}\right)=0$, then $\pi_{2}\left(\varphi_{1}, \varphi_{2}\right)=0$ would follow; a contradiction. But even $\varphi_{1}\left(\left\{\bar{p}_{1}\right\}\right)>0$ cannot be the case, since then there exists an $\varepsilon>0$ such that $\pi_{1}\left(\bar{p}_{1}-\varepsilon, \varphi_{2}\right)>\pi_{1}\left(\varphi_{1}, \varphi_{2}\right)$.

Finally, we claim that $p_{2}<p_{2}^{l}$, which in turn implies by (i) that both firms prefer playing the game with the less efficient firm as the leader to playing the simultaneous-move game. Suppose that $\underline{p}_{2} \geq p_{2}^{l}$; but then, by applying the auxiliary statements (iv), (ii) and (iii), for any price $p_{1}^{h}$ maximizing function $H\left(\cdot, p_{2}^{l}\right)$

$$
\pi_{1}\left(\varphi_{1}, \varphi_{2}\right)=\pi_{1}\left(\bar{p}_{1}, \varphi_{2}\right)<\pi_{1}\left(\bar{p}_{1}, p_{2}^{l}\right) \leq \pi_{1}\left(p_{1}^{h}, p_{2}^{l}\right)=\pi^{h}\left(p_{2}^{l}\right)=\pi_{1}\left(p_{2}^{l}, \varphi_{2}\right)
$$

would follow. Hence, $\left(\varphi_{1}, \varphi_{2}\right)$ cannot be a mixed-strategy equilibrium of the simultaneous-move game and therefore, we must have $\underline{p}_{2}<p_{2}^{l}$.

Regarding Theorem 3 the more efficient firm prefers the follower's position because then it can force the less efficient firm to set a low price. By setting a low price the less efficient firm prevents itself from being undercut by the more efficient firm.

We want to point out that applying another tie-breaking rule $T_{i}$ in case of equal prices for the game in which the less-efficient firm is the exogenously given first mover does only alter the result of Theorem 3 slightly in one special case. In particular, the only difference arises, if we apply the other extreme tie-breaking rule which puts the less efficient firm to the residual demand curve, that is, $T_{1}\left(p, q_{2}\right):=D(p)$ and $T_{2}\left(p, q_{1}\right):=\left(D(p)-q_{1}\right)^{+}$. In this case the more efficient firm's best replies to price $p_{2}^{l}$ are $p_{2}^{l}$ and $p_{1}^{h}$. To escape this uncertainty the less efficient firm will set a price slightly below $p_{2}^{l}$ and thus, resulting in an $\varepsilon$-equilibrium.

Finally, to illustrate our results we will consider the following numerical example:

Example 1. Let $D(p)=1-p, c_{1}(q)=\frac{1}{4} q^{2}$ and $c_{2}(q)=q^{2}$.

Observe that Assumption 4 is satisfied since $\frac{1}{4} \in\left(0,-\frac{1}{5}+\frac{\sqrt{6}}{5}\right]$. We have $s_{1}(p)=\min \{2 p, 1\}, s_{2}(p)=p / 2$ and $D_{1}^{r}(p)=(1-3 p / 2)^{+}$for any $p \in[0,1]$. One can easily derive that $P_{1}^{*}=\{14 / 33\}$ and $\pi^{*}=4 / 33$. If firm 1 is the leader, then it will set price $14 / 33$ and firm 2 will follow with the same price by Proposition 1 . In addition, we have $p_{1}^{L}=\frac{3}{5}-\frac{2}{165} \sqrt{429} \approx 0.34894$. Now we turn to the game having firm 2 as the first mover. ${ }^{7}$ For this game we have $G(p)=p(1-p)-\frac{1}{4}(1-p)^{2}$ for any $p \geq p_{1}^{L}, h\left(p_{1}, p_{2}\right)=\left(1-p_{1}-\frac{p_{2}}{2}\right)^{+}$and

\footnotetext{
${ }^{7} \mathrm{We}$ do not consider the simultaneous-move game because it is a very difficult and tedious task to calculate the mixed-strategy equilibrium for Example 1.
} 
$H\left(p_{1}, p_{2}\right)=p_{1}\left(1-p_{1}-\frac{p_{2}}{2}\right)^{+}-\frac{1}{4}\left(\left(1-p_{1}-\frac{p_{2}}{2}\right)^{+}\right)^{2}$ for any $p_{1} \geq p_{2} \geq p_{1}^{L}$. If problem $\max _{p_{1} \in\left[p_{2}, 1\right]} H\left(p_{1}, p_{2}\right)$ has an interior solution, i.e., $p_{2} \in\left[p_{1}^{L}, \frac{6}{13}\right)$, then we have $p_{1}=\frac{3}{5}-\frac{3}{10} p_{2}$. Next we can derive

$$
\pi^{h}\left(p_{2}\right)= \begin{cases}\frac{1}{20} p_{2}^{2}-\frac{1}{5} p_{2}+\frac{1}{5}, & \text { if } p_{2} \in\left[p_{1}^{L}, \frac{6}{13}\right] \\ -\frac{33}{16} p_{2}^{2}+\frac{7}{4} p_{2}-\frac{1}{4} p_{2}, & \text { if } p_{2} \in\left(\frac{6}{13}, \frac{2}{3}\right) ; \\ 0, & \text { if } p_{2} \in\left[\frac{2}{3}, 1\right] .\end{cases}
$$

As a solution of equation $G\left(p_{2}\right)=\pi^{h}\left(p_{2}\right)$ we obtain $p_{2}^{l}=\frac{17}{26}-\frac{1}{26} \sqrt{55} \approx$ 0.36861 . Furthermore, by maximizing $H\left(p_{1}, p_{2}^{l}\right)$ with respect to $p_{1}$ we get $p_{1}^{h} \approx 0.48942$. Thus, firm 2 sets price $p_{2}^{l} \approx 0.36861$ and firm 1 follows with price $p_{1}^{h} \approx 0.48942$.

\section{A multi-period timing game}

The timing game analyzed in Section 3 was quite simple. Next, we will investigate for the case of strictly convex cost functions a multi-period timing game considered by Deneckere and Kovenock (1988) in which the firms have repeatedly the opportunity to fix their prices. Before we proceed let us summarize the results obtained through Proposition 2 and Theorem 3. If we denote the equilibrium profits of the firms achieved as a leader, a follower and a simultaneous-mover by $\pi_{i}^{L}, \pi_{i}^{F}$, and $\pi_{i}^{S}$ respectively $^{8}$, then under Assumptions 1-4 we have

$$
\pi_{1}^{L}<\pi_{1}^{S}<\pi_{1}^{F} \quad \text { and } \quad \pi_{2}^{S}<\pi_{2}^{L},
$$

which follow from Proposition 2 and Theorem 3.

The firms have $T$ periods to set their prices at times $t / T$ where $t \in$ $\{0,1, \ldots, T-1\}$. Let $\tau:=1 / T$ stand for the time elapsing between two periods. We assume that the firms play a game with observable delay; that is, they are both aware of whenever they play a simultaneous-move subgame. Moreover, we suppose that the consumers' demand is independent of the timing of price announcements and that the sales will be determined when both firms have fixed their prices. We shall assume that the firms discount their profits continuously with a discount rate $r$, and let $\delta:=e^{-r \tau}$.

We calculate the subgame-perfect equilibrium of the multi-period timing game through backwards induction. If no price announcements are made until the final period $T-1$, then they both announce their prices in the final

\footnotetext{
${ }^{8}$ If the simultaneous-move game does not have a unique equilibrium, then we can pick an arbitrary mixed-strategy equilibrium.
} 
Table 1: Payoffs of the subgame starting in period $T-2$.

\begin{tabular}{|c|c|c|}
\hline & Announce & Wait \\
\hline Announce & $\left(\delta^{T-2} \pi_{1}^{S}, \quad \delta^{T-2} \pi_{2}^{S}\right)$ & $\left(\delta^{T-1} \pi_{1}^{L}, \quad \delta^{T-1} \pi_{2}^{F}\right)$ \\
\hline Wait & $\left(\delta^{T-1} \pi_{1}^{F}, \quad \delta^{T-1} \pi_{2}^{L}\right)$ & $\left(\delta^{T-1} \pi_{1}^{S}\right.$ \\
\hline
\end{tabular}

period since otherwise, they will earn zero profits. Hence, the firms will play a simultaneous-move game. Now if no announcements occur until period $T-2$, then the firms play a $2 \times 2$ bimatrix game with both firms deciding about making an announcement in period $T-2$. If both set their prices in period $T-2$, then they play a simultaneous-move game at time $(T-2) / T$ and earn $\delta^{T-2} \pi_{i}^{S}$ profits; while if both firms delay their announcements to the next period, they earn $\delta^{T-1} \pi_{i}^{S}$ profits. If only the more efficient firm reveals its price in period $T-2$, then the less efficient firm reveals its price in the next period resulting in $\delta^{T-1} \pi_{1}^{L}$ and $\delta^{T-1} \pi_{2}^{F}$ profits respectively. Otherwise, the less efficient firm sets its price in period $T-2$ and the more efficient firm in period $T-1$, which yields them $\delta^{T-1} \pi_{2}^{L}$ and $\delta^{T-1} \pi_{1}^{F}$ profits. Without loss of generality we may assume that $\pi_{1}^{S} / \pi_{1}^{F}<\delta$ because this can be achieved by choosing a sufficiently large $T$. It can be easily verified by (5) and Table 1 that in the equilibrium of the subgame played in period $T-2$ the less efficient firm announces its price in period $T-2$, while the more efficient firm delays its announcement to period $T-1$.

By induction we establish that in the subgame starting in period $T-k(k \in$ $\{3,4, \ldots, T\})$ the less efficient firm immediately announces its price and the more efficient firm delays its announcement to the next period. Suppose that no announcement has been made before period $T-k$. If both set their prices in period $T-k$, then they obtain $\delta^{T-k} \pi_{i}^{S}$ profits; while if both firms delay their announcements to period $T-k+1$, then by the induction hypothesis the less efficient firm moves in period $T-k+1$ and the more efficient firm moves in period $T-k+2$ resulting $\delta^{T-k+2} \pi_{2}^{L}$ and $\delta^{T-k+2} \pi_{1}^{F}$ profits respectively. If only the more efficient firm reveals its price in period $T-k$, then the less efficient firm sets its price in period $T-k+1$ yielding $\delta^{T-k+1} \pi_{1}^{L}$ and $\delta^{T-k+1} \pi_{2}^{F}$ profits. Otherwise, the less efficient firm sets its price in period $T-k$ and the more efficient firm in period $T-k+1$, which yields them $\delta^{T-k+1} \pi_{2}^{L}$ and $\delta^{T-k+1} \pi_{1}^{F}$ profits. Now it can be easily checked by (5) and looking at Table 2 that for the subgame starting in period $T-k$ the less efficient firm moves immediately, while the more efficient firm moves in the next period. Therefore it follows that the multi-period timing game confirms the result obtained in Theorem 3; that is, the less efficient firm is the endogenously determined first-mover. 
Table 2: Payoffs of the subgame starting in period $T-k$.

\begin{tabular}{|c|c|c|c|c|}
\hline & \multicolumn{2}{|c|}{ Announce } & \multicolumn{2}{|c|}{ Wait } \\
\hline Announce & $\left(\delta^{T-k} \pi_{1}^{S}\right.$ & $\left(\delta^{T-k} \pi_{2}^{S}\right)$ & $\left(\delta^{T-k+1} \pi_{1}^{L}\right.$ & $\left.\delta^{T-k+1} \pi_{2}^{F}\right)$ \\
\hline Wait & $\left(\delta^{T-k+1} \pi_{1}^{H}\right.$ & $\left.\delta^{T-k+1} \pi_{2}^{L}\right)$ & $\left(\delta^{T-k+2} \pi_{1}^{H}\right.$ & $\left.\delta^{T-k+2} \pi_{2}^{L}\right)$ \\
\hline
\end{tabular}

\section{Concluding remarks}

Theorem 3 is surprising because one would expect that the more efficient firm moves first and acts as a price leader. Our result that the less efficient firm moves first can be explained by the fact that the less efficient firm as a first mover leaves a far more favourable residual demand than as a second mover and than as a simultaneous mover. For real life situations in which the less efficient firm sets a sufficiently low price in order to prevent a price war we refer to Boyer and Moreaux (1987, p. 190).

It would be nice to extend Theorem 3 to oligopolies in which many exogenously given orders of moves are possible. Hence, to determine the endogenous order of moves we have to compare, among other cases, two payoffs resulting from nondegenerated mixed-strategy equilibria. We could solve the duopolistic case quite easily because the two sequential-move games have equilibria in pure strategies. Therefore, to solve the case of more than two firms appears to be a very difficult task because of the complexity of Bertrand-Edgeworth games with convex cost functions.

\section{References}

[1] Boyer M, Moreaux M (1987) Being a Leader or a Follower: Reflections on the Distribution of Roles in Duopoly. International Journal of Industrial Organization 5(2): 175-192

[2] Canoy M (1996) Product Differentiation in a Bertrand-Edgeworth Duopoly. Journal of Economic Theory 70(1): 158-179

[3] van Damme E, Hurkens S (1998) Endogenous Price Leadership. Economics Working Paper No. 289, Universitat Pompeu Fabra

[4] van Damme E, Hurkens S (1999) Endogenous Stackelberg Leadership. Games and Economic Behavior 28(1): 105-129

[5] Deneckere R, Kovenock D (1988) Price Leadership. CMSEMS Discussion Paper No. 773, Northwestern University 
[6] Deneckere R, Kovenock D (1992) Price Leadership. Review of Economic Studies 59(1): 143-162

[7] Dowrick S (1986) von Stackelberg and Cournot duopoly: choosing roles. Rand Journal of Economics 17(2): 251-260

[8] Furth D, Kovenock D (1993) Price Leadership in a Duopoly With Capacity Constraints and Product Differentiation. Journal of Economics (Zeitschrift für Nationalökonomie) 57(1): 1-35

[9] Gal-Or E (1985) First mover and second mover advantages. International Economic Review 26(2): 649-653

[10] Gangopadhyay S (1993) Simultaneous vs Sequential Move Price Games: A comparison of equilibrium payoffs. Discussion Paper No. 93-01, Indian Statistical Institute

[11] Hamilton JH, Slutsky SM (1990) Endogenous Timing in Duopoly Games: Stackelberg or Cournot Equilibria. Games and Economic Behavior 2(1): $29-46$

[12] Maskin E (1986) The Existence of Equilibrium with Price-Setting Firms. American Economic Review 76(2): 382-386

[13] Matsumura T (1999) Quantity-setting oligopoly with endogenous sequencing. International Journal of Industrial Organization 17(2): 289-296

[14] Matsumura T (2002) Market Instability in a Stackelberg Duopoly. Journal of Economics (Zeitschrift für Nationalökonomie) 75(1): 199-210

[15] Tirole J (1988) The Theory of Industrial Organization. MIT Press, Cambridge MA

[16] Vives X (1999) Oligopoly Pricing: Old Ideas and New Tools. MIT Press, Cambridge MA 